\title{
A phytotherapeutic approach to hand and feet dyshidrosis using vegetables (espcially mashed celeriac applied topically)
}

\section{Piotr Brzeziński', Lorenzo Martini ${ }^{1,2}$}

${ }^{1}$ University of Siena, Department of Pharmaceutical Biotechnologies, Via A. Moro 2, 53100 Siena, Italy, ${ }^{2}$ C.R.I.S.M.A. Inter University Centre for Researched Advanced Medical Systems

Corresponding author: Prof. Lorenzo Martini, E-mail: martini36@unisi.it

Sir,

This common form of eczema causes small, intensely itchy blisters on the edges of the fingers, toes, palms, and soles of the feet. It is twice as common in women as it is in men.

Because of the association with seasonal allergies, the dyshidrotic eczema blisters are known to erupt more frequently during the spring allergy season. The blisters may last up to three weeks before they begin to dry and can sometimes be large and painful. As the blisters dry, they may turn into skin cracks or cause the skin to feel thick and spongy, especially if you've been scratching the area. Deep blisters on the sides of the feet are typical of dyshidrotic eczema.

Doctors also may refer to dyshidrotic eczema as: Cheiropompholyx; Dyshidrosis; Foot-and-hand eczema; Pompholyx; Vesicular eczema; Palmoplantar eczema.

There is no cure for dyshidrotic eczema, but the good news is, in many cases it's manageable. And like all types of the condition, it isn't contagious. You cannot contract dyshidrotic eczema from another person, or give it to someone else.

All types of eczema cause itching and redness. But some, like dyshidrotic eczema, look and act slightly different than others. It is possible to have dyshidrotic eczema and another form of eczema such as contact dermatitis, at the same time [1].
Symptoms of dyshidrotic eczema include: Deep-set blisters on the edges of the fingers, toes, palms and soles of the feet; Itching; Redness; Flaking; Scaly, cracked skin; Pain [2].

Dyshidrotic eczema blisters can be hard to see on the palms and fingers because the skin is thicker here.

It's important to understand which type of eczema one may have and also know well the symptoms and triggers, so that it can be better treated and managed it $[3,4]$.

Dyshidrotic eczema usually appears in adults ages 20 through 40 but it can also affect children. People with contact dermatitis, atopic dermatitis or hay fever, are at higher risk of developing dyshidrotic eczema. Dyshidrotic eczema seems to run in families, so if somebody has a close relative with this form of eczema, the chance of also developing it is increased.

There are some common triggers for dyshidrotic eczema:

- Stress,

- Pollen,

- Moist hands and feet from excessive sweating or prolonged contact with water,

- Nickel in everyday objects such as jewelry, keys, cell phones, eyeglass frames, stainless steel items, and metal buttons, snaps and zippers,

- Nickel in foods such as cocoa, chocolate, soy beans, oatmeal, nuts, almonds, fresh and dried legumes, and canned foods,

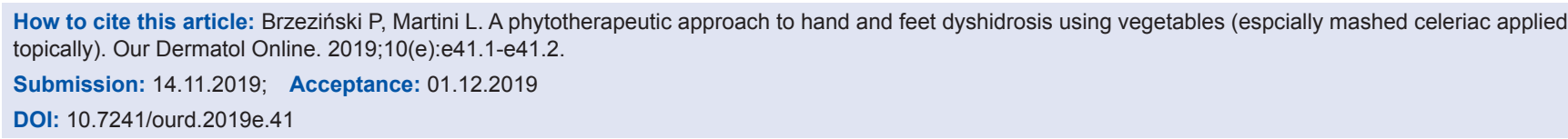


- Cobalt in everyday objects such as cobalt-blue colored dishware, paints and varnishes; certain medical equipment; jewelry; and in metal snaps, buttons and zippers,

- Cobalt in foods such as clams, fish, leafy green vegetables, liver, milk, nuts, oysters, and red meat Psoriasis of whichever type,

- Chromium salts used in the manufacturing of cement, mortar, leather, paints and anticorrosives [5].

At-home treatment for dyshidrotic eczema includes soaking hands and feet in cool water or applying compresses for 15 minutes to the affected area two to four times a day followed by a rich moisturizer or a skin barrier repair cream.

For more severe cases of dyshidrotic eczema, a provider may prescribe topical steroids, TCIs or phototherapy. Additionally, the provider may drain the blisters in-office, and/or give a dose of Botox in the hands and feet to reduce sweating and wetness, which are known triggers for this form of eczema.

Dyshidrotic eczema has the tendency to get infected, which can delay clearing of symptoms. If a serious infection is suspected it may mean that an infection in the area where the eczema appears, and much attention for this case must be payed as well.

Atopic dermatitis and contact dermatitis may look like dyshidrotic eczema.

There is no surefire way to prevent dyshidrotic eczema. However, good skin care and moisturizing can help strengthen skin against irritation, so that it doesn't flare up, or get worse. The most important thing to remember is to be consistent.

Common remedies all the dermatologists all over the world administer are:

Antihystamines to be taken orally

Pomades containing high dosages of corticosteroids.

The AA have decided to approach the specific concern by the aids of phytotherapeutic agents and so they have created a mix of vegetal antihystamine extracts to assume orally:

Vaccinium myrtillus seed extract [5-7]
Capparis spinosa fruit extract

Propolis extract

And a pomade containing 15\% of Apium graveolens rapaceum (Printz) root extract.

The pomade is a generic emulsion made of petrolatum, glycerin, ceteareth20 and polysorbate 60 .

They have recruited 10 volunteers:

They have prayed to apply the pomade for 5 days to the former 5 subjects and the other 5 were prayed to apply the mashed apium rapaceum root directly on their hands.

In all the 10 days a complete remission is noticeable after 5 days, even if the volunteers who used mashed apium rapaceum could observe a remission and the disappearance of the itching after the $1^{\text {st }}$ or $2^{\text {nd }}$ day.

This is very interesting, because it is known that all the excipients of a cosmetic item tend to decelerate the release of the biological (or chemical) principle contained.

\section{REFERENCES}

1. Gupta M. Hand eczema and patch testing - A clinico-allergiological study. Our Dermatol Online. 2019;10:255-8.

2. Colomb-Lippa D, Klingler AM. Dyshidrosis. J Am Acad Phys Assist. 2011;24:54.

3. Puri N, Puri A. A study on contact dermatitis to hair dye and henna. Our Dermatol Online. 2013;4:545-8.

4. Alouani I, Dikhaye S, Zizi N. Eyebrows contact dermatitis miming angioedema. Our Dermatol Online. 2019;10:390.

5. Ge Y, Li Y, Bai Y, Yuan C, Wu C, Hu Y. Intelligent gelatin/oxidized chitin nanocrystals nanocomposite films containing black rice bran anthocyanins for fish freshness monitorings. Int J Biol Macromol. 2019;pii: S0141-8130(19)37548-8.

6. Diaconeasa Z, Iuhas CI, Ayvaz H, Rugină D, Stanilă A, Dulf F, et al. Phytochemical characterization of commercial processed blueberry, blackberry, blackcurrant, cranberry, and raspberry and their antioxidant activity. Antioxidants (Basel). 2019;8:pii: E540.

7. Burdulis D, Ivanauskas L, Dirse V, Kazlauskas S, Razukas A. Study of diversity of anthocyanin composition in bilberry (Vaccinium myrtillus L.) fruits. Medicina (Kaunas). 2007;43:971-7.

Copyright by Piotr Brzeziński, et al. This is an open-access article distributed under the terms of the Creative Commons Attribution License, which permits unrestricted use, distribution, and reproduction in any medium, provided the original author and source are credited.

Source of Support: Nil, Conflict of Interest: None declared. 